\title{
Efficacy and safety of oral compared with intravenous tranexamic acid in reducing blood loss after primary total knee and hip arthroplasty: a meta-analysis
}

Xiaozhen $\mathrm{Han}^{1 \dagger}{ }^{1 \dagger}$ Guiqing Gong ${ }^{1 \dagger}$, Naili $\mathrm{Han}^{2}$ and Mei Liu ${ }^{3^{*}}$ (D)

\begin{abstract}
Background: Tranexamic acid (TXA) is an anti-fibrinolytic agent successfully preventing blood loss when using intravenously (IV) in total hip arthroplasty (THA) and total knee arthroplasty (TKA). An oral administration, which is available on blood sparing, has been reported exhibit profound cost-saving benefits. The aim of this meta-analysis is to investigate whether the administration of oral and intravenous tranexamic acid postoperatively has equivalent blood-sparing properties in these patients.

Methods: The online electronic databases were searched for eligible literatures updated on September 2018. Studies assessing the effect between oral TXA and intravenous TXA (IV-TXA) in those undergoing TKA or THA were included. All the data were pooled with the corresponding 95\% confidence interval (Cl) using RevMan software. Based on the heterogeneity, we performed a systematic analysis to explore the overall results across the included studies.

Results: Nine studies met our inclusion criteria. No significant differences were identified with regard to the $\mathrm{Hb}$ drop $(\mathrm{SMD}=-0.03,95 \% \mathrm{Cl}=-0.18-0.12, P=0.67)$, total $\mathrm{Hb}$ loss $(\mathrm{SMD}=0.10,95 \% \mathrm{Cl}=-0.06-0.26, P=0.24)$, total blood loss $(\mathrm{SMD}=-0.00,95 \% \mathrm{Cl}=-0.20-0.20, P=1.00)$, transfusion rate $(\mathrm{OR}=0.77,95 \% \mathrm{Cl}=0.54-1.10, P=0.14)$, DVT rate $(\mathrm{OR}=0.58,95 \% \mathrm{Cl}=0.19-1.75, P=0.33)$, and length of hospital stay $(\mathrm{SMD}=-0.05,95 \% \mathrm{Cl}=-0.28-0.17, P=0.63)$ between the oral groups and intravenous group.

Conclusion: The blood-sparing efficacy of oral TXA is similar to that of the intravenous forms in the setting of THA and TKA. Considering the cost-benefit superiority and ease of administration of oral TXA, further studies and clinical trials are required to further identify the optimal administration for THA and TKA.
\end{abstract}

Keywords: Tranexamic acid, Total hip arthroplasty, Total knee arthroplasty, Meta-analysis

\section{Background}

Patients who suffer from osteoarthritis, rheumatoid arthritis, fractures, or the knee or hip cancer often need total knee and hip arthroplasty (TKA and THA) [1]. Although TKA and THA have been identified as an effective management in improving physical function and relieving pain, these procedures can result in high risk of perioperative

\footnotetext{
*Correspondence: 66799073@qq.com

${ }^{+}$Xiaozhen Han and Guiqing Gong contributed equally to this work.

${ }^{3}$ Department of Intensive Care Unit, Wuhan No.1 Hospital, No.215

Zhongshan Ave, Wuhan 430022, Hubei, China

Full list of author information is available at the end of the article
}

anemia, which can be associated with increasing morbidity and cost. Thus, a considerable number of patients require blood transfusions to prevent anemia $[2,3]$.

Finding effective methods for minimizing the risk of transfusion and perioperative blood loss have been a goal for surgeons to perform total TKA and THA [3, 4]. Surgeons have implemented numerous methods to achieve this goal, particularly the using of anti-fibrinolytic agents, such as tranexamic acid (TXA).

Tranexamic acid is a synthetic amino acid that functions by competitively inhibiting the activation of plasminogen, thereby inhibiting clot degradation [5], which has been

(c) The Author(s). 2018 Open Access This article is distributed under the terms of the Creative Commons Attribution 4.0 International License (http://creativecommons.org/licenses/by/4.0/), which permits unrestricted use, distribution, and reproduction in any medium, provided you give appropriate credit to the original author(s) and the source, provide a link to the Creative Commons license, and indicate if changes were made. The Creative Commons Public Domain Dedication waiver (http://creativecommons.org/publicdomain/zero/1.0/) applies to the data made available in this article, unless otherwise stated. 
identified as effectively reducing blood loss and the risk of adverse outcomes following THA and TKA [6-8].

Tranexamic acid can be administered intravenously (IV), topically (intra-articular), and orally. However, the optimal administration of TXA administration remains controversial [9-11]. Recently, several studies have been published to evaluate the effects of the TXA administration routes between oral and IV-TXA, while the efficacy and safety between two groups are still unknown $[12,13]$.

In this meta-analysis, we aim to explore whether oral TXA has an equivalent effect to intravenously in reducing blood loss in THA and TKA.

\section{Methods}

\section{Search strategy}

We performed the current meta-analysis based on the electronic databases: Pubmed, Embase, Cochrane library up to September 2018. The process was established to find all articles based on the MeSH terms and free key words: "Total knee replacement or arthroplasty" AND "Total hip replacement or arthroplasty" OR "tranexamic acid" AND "oral TXA" , AND "intravenous TXA". Moreover, we identified full-text papers from reference materials for further evaluation.

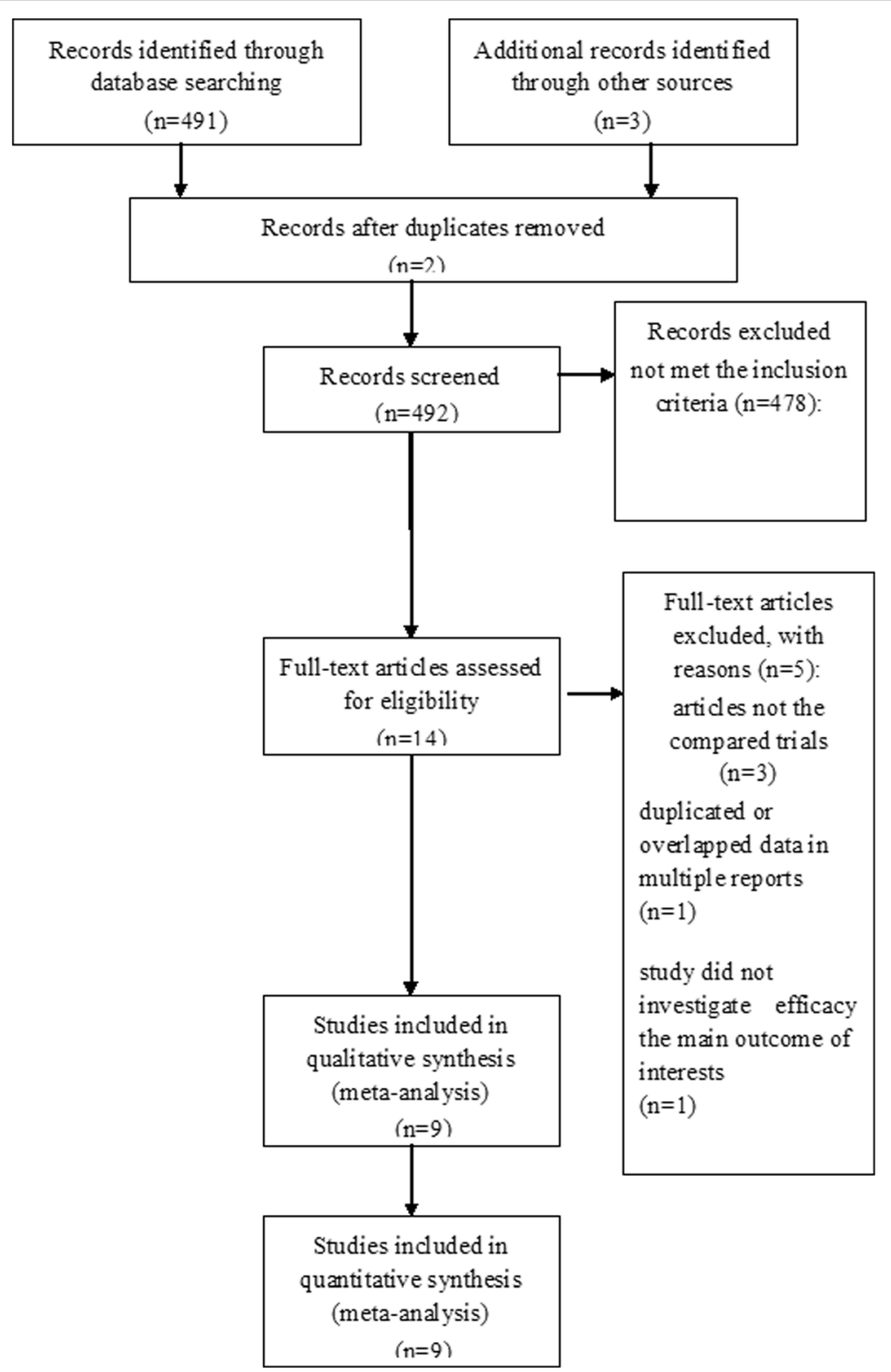

Fig. 1 PRISMA flow chart of selection process to identify studies eligible for pooling 
Table 1 the primary characteristics of the eligible studies in more detail

\begin{tabular}{|c|c|c|c|c|c|c|c|c|}
\hline \multirow[t]{2}{*}{ Studies (year) } & \multirow[t]{2}{*}{$\begin{array}{l}\text { Study } \\
\text { type }\end{array}$} & \multirow[t]{2}{*}{ Surgery } & \multicolumn{2}{|c|}{ Treatment regimen (Dosage of TXA) } & \multicolumn{2}{|c|}{$\begin{array}{l}\text { Treatment regimen } \\
\text { (number) }\end{array}$} & \multicolumn{2}{|c|}{$\begin{array}{l}\text { Treatment regimen } \\
\text { (Age) }\end{array}$} \\
\hline & & & oral & intravenous & oral & intravenous & oral & intravenous \\
\hline Kayupovt, 2017 & $\mathrm{RCT}$ & THA & $1950 \mathrm{mg} / \mathrm{kg}$ & $1000 \mathrm{mg}$ & 40 & 43 & 60 & 55 \\
\hline Yuan, 2017 & $\mathrm{RCT}$ & TKA & $40 \mathrm{mg} / \mathrm{kg}$ & $20 \mathrm{mg} / \mathrm{kg}$ & 140 & 140 & 63.2 & 63.7 \\
\hline Fillingham, 2016 & $\mathrm{RCT}$ & TKA & 1950 mg & $1000 \mathrm{mg}$ & 34 & 37 & 62 & 63 \\
\hline Irwin, 2013 & RCS & TKA and THA & 25 mg/kg (maximum $2 \mathrm{~g}$ ) & 15 mg/kg (maximum 1.2g) & 302 & 2698 & 67.6 & 68.2 \\
\hline Zohar, 2004 & $\mathrm{RCT}$ & TKA & $4000 \mathrm{mg}$ & $10 \mathrm{mg} / \mathrm{kg}$ for $12 \mathrm{~h}$ & 20 & 20 & 69 & 73 \\
\hline Cao, 2018 & $\mathrm{RCT}$ & THA & $2000 \mathrm{mg}$ & $20 \mathrm{mg} / \mathrm{kg}$ & 54 & 54 & 55.7 & 55.7 \\
\hline Gortemoller, 2017 & RCS & TKA and THA & $1950 \mathrm{mg}$ & $1000 \mathrm{mg}$ & 165 & 165 & 67 & 68 \\
\hline Luo, 2017 & RCS & THA & $2000 \mathrm{mg}$ & $20 \mathrm{mg} / \mathrm{kg}$ & 60 & 60 & 67.6 & 66.98 \\
\hline Wang, 2018 & $\mathrm{RCT}$ & TKA & 2000 mg & $20 \mathrm{mg} / \mathrm{kg}$ & 60 & 60 & 63.91 & 66.9 \\
\hline
\end{tabular}

TXA tranexamic acid, THA total hip arthroplasty, TKA total knee arthroplasty, $R C T$ randomized controlled trial, $R C S$ retrospective cohort study

\section{Eligibility criteria}

Studies were included in the meta-analysis should meet the following criteria: [1] articles that enrolled total knee/hip arthroplasty patients treated with TXA; [2] the studies are designed as comparing TXA administered via intravenous (IV) and oral routes; [3] the outcomes of interest were efficacy (total blood loss, total hemoglobin $(\mathrm{Hb})$ loss, $\mathrm{Hb}$ reduction, transfusion rate, length of hospital stay) and toxicity (incidence of deep vein thrombosis (DVT)), and with corresponding 95\% CIs were provided; [4] the full-text papers were only included.

\section{Quality assessment}

The quality of the search was performed separately by two reviewers. We use the New-castle-Ottawa Quality Assessment Scale recommended by the "Cochrane Intervention Manual Systematic Review".

\section{Data extraction}

Two authors independently extracted the relevant data from each trial. Disagreement was resolved by consensus. We extracted the main categories based on the following: first author family name, year of publication, study type, surgery, dosage of TXA patient number, age, and outcomes measures. We extracted the corresponding Std.Mean Difference (SMD) and odds ratios (ORs) with $95 \%$ confidence interval $(95 \% \mathrm{CI})$ to describe the endpoints of interest.

\section{Statistical analysis}

The Cochrane Collaborations have offered Review Manager Software (RevMan5.3) for statistical analysis.(Revman; The Cochrane collaboration Oxford, United Kingdom). The chi-square was used to assess the significance of heterogeneity [14]. $\mathrm{I}^{2}$ value larger than $50 \%$ suggested high degree of heterogeneity [15]. When there was high heterogeneity among studies, the randomed-effects model was used. Otherwise, the fixed effects model was used. A $P$ value less than 0.05 was identified as statistically significant difference. Findings of our meta-analysis were shown in forest plots. The Begg test and the Egger test were conducted to evaluate publication bias.

\section{Results}

\section{Study selection process}

A total of 492 articles were considered possibly eligible. Based on the criteria described in the methods, 14 articles were further eliminated by reading the full articles, but some did not provide enough detail of outcomes of two

\begin{tabular}{|c|c|c|c|c|c|c|c|c|c|c|c|}
\hline \multirow[b]{2}{*}{ Study or Subgroup } & \multicolumn{3}{|c|}{ Experimental } & \multicolumn{3}{|c|}{ Control } & \multicolumn{3}{|c|}{ Std. Mean Difference } & \multirow{2}{*}{$\begin{array}{l}\text { Std. Mean Difference } \\
\text { IV, Fixed, } 95 \% \mathrm{Cl}\end{array}$} & \\
\hline & Mean & SD & Total & Mean & SD & Total & Weight & IV, Fixed, $95 \% \mathrm{Cl}$ & & & \\
\hline Fillingham, 2016 & 3.45 & 0.93 & 34 & 3.31 & 0.95 & 37 & $10.5 \%$ & $0.15[-0.32,0.61]$ & & + & \\
\hline Kayupovt, 2017 & 3.67 & 1.2 & 40 & 3.53 & 1.2 & 43 & $12.3 \%$ & $0.12[-0.32,0.55]$ & & & \\
\hline Luo, 2017 & 3.48 & 1.32 & 60 & 3.58 & 1.07 & 60 & $17.8 \%$ & $-0.08[-0.44,0.28]$ & & & \\
\hline Wang, 2018 & 2.91 & 1.73 & 60 & 3.13 & 0.89 & 60 & $17.8 \%$ & $-0.16[-0.52,0.20]$ & & th & \\
\hline Yuan, 2017 & 2.9 & 0.43 & 140 & 2.92 & 0.41 & 140 & $41.6 \%$ & $-0.05[-0.28,0.19]$ & & & \\
\hline Total $(95 \% \mathrm{Cl})$ & & & 334 & & & 340 & $100.0 \%$ & $-0.03[-0.18,0.12]$ & & & \\
\hline \multicolumn{6}{|c|}{$\begin{array}{l}\text { Heterogeneity: } \mathrm{Ch}^{2}=1.59, \mathrm{df}=4(P=0.81) ; \mathrm{I}^{2}=0 \% \\
\text { Test for overall effect: } Z=0.43(P=0.67)\end{array}$} & & & & $\stackrel{\longmapsto}{-10}$ & $\begin{array}{l}0 \\
0 \\
\text { oral intravenous }\end{array}$ & 10 \\
\hline
\end{tabular}

Fig. 2 Pooled analysis of $\mathrm{Hb}$ drop between oral administration and intravenous administration 


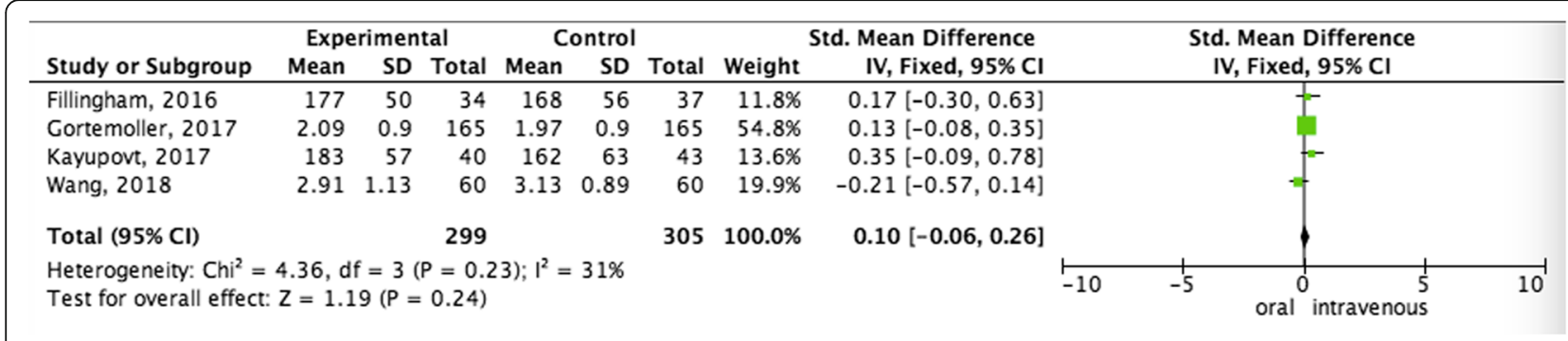

Fig. 3 Pooled analysis of total $\mathrm{Hb}$ loss between oral administration and intravenous administration

approaches. Therefore, a final total of 9 studies [11, 16-23] with included (Fig. 1). Table 1 describes a brief description of these eligible studies. All included studies in this study were based on moderate to high quality evidence.

\section{Clinical and methodological heterogeneity Pooled analysis of $\mathrm{Hb}$ drop between oral administration and intravenous administration}

Pooled data of the $\mathrm{Hb}$ drop from five studies showed that no statistical differences were observed in terms of favoring oral administration compared with the intravenous administration group (SMD $=-0.03,95 \% \mathrm{CI}=-0.18-0.12, P=0.67$ ) (Fig. 2).

\section{Pooled analysis of total $\mathrm{Hb}$ loss between oral administration and intravenous administration}

In terms of total $\mathrm{Hb}$ loss, no significant differences compared oral administration and intravenous administration was observed $(\mathrm{OR}=0.73 ; 95 \% \mathrm{CI}=0.51-1.05$; $p=0.09$ ) (Fig. 3).

\section{Pooled analysis of total blood loss between oral} administration and intravenous administration

Fixed-effect model was used to pool the total blood loss data, since the heterogeneity across the four studies was insignificant. The pooled data showed that oral administration did not increase total blood loss $\quad(\mathrm{SMD}=-0.00,95 \% \mathrm{CI}=-0.20-0.20, \quad P=1.00)$ than intravenous administration therapy (Fig. 4).
Pooled analysis of transfusion rate between oral administration and intravenous administration

The pooling transfusion rate data did not achieve advantage in the oral administration $(\mathrm{OR}=0.77,95 \% \mathrm{CI}=$ $0.54-1.10, P=0.14)$. In other words, oral administration compared to intravenous administration did not increase the rate of transfusion (Fig. 5).

\section{Pooled analysis of DVT rate between oral administration and intravenous administration}

The pooled data showed that oral administration did not increase the rate of DVT $(\mathrm{OR}=0.58,95 \% \mathrm{CI}=0.19-1.75$, $P=0.33$ ) than intravenous administration (Fig. 6).

\section{Pooled analysis of length of hospital stay between oral administration and intravenous administration}

The pooling analysis revealed that there was no difference in length of hospital stay between oral administration and intravenous administration $(\mathrm{SMD}=-0.05,95 \% \mathrm{CI}=-0.28-$ $0.17, P=0.63$ ) (Fig. 7).

\section{Discussion}

Tranexamic acid has become a widely used to decrease blood loss and transfusion rates following THA and TKA, mainly administrated in the IV in previous studies [8, 24-26]. Compared with intravenous TXA, oral TXA is convenient to administer, reaches cost-benefit advantage, and increases the safety $[11,19]$. However, limited research has been done on the use of oral TXA in total joint arthroplasty, and the optimal regimen for TXA has remained uncertain, which have been extensively explored in recent RCTs [27-29].



Fig. 4 Pooled analysis of total blood loss between oral administration and intravenous administration 


\begin{tabular}{|c|c|c|c|c|c|c|c|c|c|}
\hline Study or Subgroup & \multicolumn{2}{|c|}{ Experimental } & \multicolumn{2}{|c|}{ Control } & Weight & $\begin{array}{c}\text { Odds Ratio } \\
\text { M-H, Fixed, } 95 \% \mathrm{Cl}\end{array}$ & \multicolumn{3}{|c|}{$\begin{array}{c}\text { Odds Ratio } \\
\text { M-H, Fixed, } 95 \% \mathrm{CI}\end{array}$} \\
\hline Fillingham, 2016 & 1 & 34 & 1 & 37 & $1.3 \%$ & $1.09[0.07,18.15]$ & & & \\
\hline Gortemoller, 2017 & 6 & 165 & 5 & 165 & $6.7 \%$ & $1.21[0.36,4.04]$ & & & \\
\hline Inwin, 2013 & 14 & 302 & 215 & 2698 & $57.1 \%$ & $0.56[0.32,0.98]$ & & & \\
\hline Kayupovt, 2017 & 3 & 40 & 1 & 43 & $1.2 \%$ & $3.41[0.34,34.17]$ & & & \\
\hline Luo, 2017 & 4 & 60 & 5 & 60 & $6.5 \%$ & $0.79[0.20,3.08]$ & & & \\
\hline Wang, 2018 & 2 & 60 & 4 & 60 & $5.4 \%$ & $0.48[0.09,2.74]$ & & & \\
\hline Yuan, 2017 & 15 & 140 & 15 & 140 & $18.5 \%$ & $1.00[0.47,2.13]$ & & & \\
\hline Zohar, 2004 & 4 & 20 & 3 & 20 & $3.3 \%$ & $1.42[0.27,7.34]$ & & & \\
\hline Total $(95 \% \mathrm{Cl})$ & & 821 & & 3223 & $100.0 \%$ & $0.77[0.54,1.10]$ & & & \\
\hline Total events & 49 & & 249 & & & & & & \\
\hline $\begin{array}{l}\text { Heterogeneity: } \mathrm{Chi}^{2}= \\
\text { Test for overall effect }\end{array}$ & $\begin{array}{l}4.71, \mathrm{df}= \\
Z=1.46\end{array}$ & $\begin{array}{l}=7(P= \\
(P=0 .\end{array}$ & $\begin{array}{l}0.70) ; 1^{2} \\
\text { 14) }\end{array}$ & $=0 \%$ & & & 0.10 .2 & 0.5 oral $^{1}$ & $\begin{array}{|ccc|}1 & 1 & 10 \\
\text { intravenous } & 5 & \end{array}$ \\
\hline
\end{tabular}

Fig. 5 Pooled analysis of transfusion rate between oral administration and intravenous administration

Our meta-analysis aims to assess the effects of intravenous or topical routes of administration.

The results of this study suggested that no significant differences were found in blood-sparing management between oral and IV TXA. This finding is comparable to the findings of a recent meta-analysis that shown that oral TXA provided equivalent blood-sparing efficacy when compared with intravenous routes [23].

The $\mathrm{Hb}$ drop accounted for $>60 \%$ of total blood loss in total joint arthroplasty [30, 31]. Due to the blood loss may leading to postoperative hypoxemia, the blood transfusion is required. However, blood transfusion is associated with adverse effects and increases the risk of complications resulting from hypervolemia [32-34]. Hence, rational and effective method for minimizing perioperative blood loss is needed. Previous studies have reported that IV-TXA has beneficial effects on blood-sparing, which has been widely used in patients undergoing both TKA and THA. However, IV administration of TXA has increased the risk of anaphylactic reaction [35]. Moreover, specific equipment is required for IV administration of TXA, which prolong the surgery time.

Recently, some RCTs have demonstrated that oral TXA administration was non-inferior to IV administration in the prevention of perioperative blood loss $[11,18,19]$. Kayupov et al. [18] found that no difference in the reduction of $\mathrm{Hb}$ was seen between two groups. Coincidentally, both Yuan et al. [19] and Fillingham et al. [11] have reported the same result. Moreover, these authors further reported that oral TXA meet similar with the IV TXA in terms of the total $\mathrm{Hb}$ loss following TKA and THA. Our meta-analysis was consistent with these results.

In terms of the transfusion rate, a RCT carried out by Kayupov et al. [18] found no significant difference between the two routes of administration following THA. Yuan et al. [19] compared the transfusion rate between oral administration and IV administration in patients who received TKA, and this difference was not statistically significantly different. This result was consistent with our findings.

DVT is a common postoperative complication, which may promote the risk of death in TKA and THA [36]. TXA has been reported to be associated with a potential higher risk of thrombotic complication, which might be due to the tendency of DVT, and plays as anti-fibrinolytic agent to promote the risk of clotting. The intravenous administration might be more likely to cause thrombus due to the higher TXA level of blood concentration. Our study found that the two routes of administration of TXA were similar in terms of the risk of DVT.

\begin{tabular}{|c|c|c|c|c|c|c|c|c|}
\hline Study or Subgroup & \multicolumn{2}{|c|}{ Experimental } & \multicolumn{2}{|c|}{ Control } & Weight & $\begin{array}{c}\text { Odds Ratio } \\
\text { M- } \mathrm{H} \text {, Fixed, } 95 \% \mathrm{Cl}\end{array}$ & \multicolumn{2}{|c|}{$\begin{array}{c}\text { Odds Ratio } \\
\text { M-H, Fixed, } 95 \% \mathrm{Cl}\end{array}$} \\
\hline Cao, 2018 & 0 & 54 & 2 & 54 & $27.4 \%$ & $0.19[0.01,4.11]$ & $\longleftarrow$ & \\
\hline Gortemoller, 2017 & 1 & 165 & 0 & 165 & $5.5 \%$ & $3.02[0.12,74.63]$ & & \\
\hline Inwin, 2013 & 1 & 302 & 13 & 2698 & $28.8 \%$ & $0.69[0.09,5.26]$ & - & \\
\hline Wang, 2018 & 0 & 60 & 1 & 60 & $16.4 \%$ & $0.33[0.01,8.21]$ & $\longleftarrow$ & \\
\hline Yuan, 2017 & 1 & 140 & 2 & 140 & $21.9 \%$ & $0.50[0.04,5.54]$ & & \\
\hline Total $(95 \% \mathrm{Cl})$ & & 721 & & 3117 & $100.0 \%$ & $0.58[0.19,1.75]$ & & \\
\hline Total events & 3 & & 18 & & & & & \\
\hline $\begin{array}{l}\text { Heterogeneity: } \mathrm{Chi}^{2}= \\
\text { Test for overall effect }\end{array}$ & $\begin{array}{l}1.68, \mathrm{df}= \\
Z=0.97\end{array}$ & $\begin{array}{l}4(P= \\
(P=0.3\end{array}$ & $\begin{array}{l}0.79) ; 1^{2} \\
33)\end{array}$ & $=0 \%$ & & & $0.5{ }^{1}$ & $1 \frac{1}{1}$ \\
\hline
\end{tabular}

Fig. 6 Pooled analysis of DVT rate between oral administration and intravenous administration 


\begin{tabular}{|c|c|c|c|c|c|c|c|c|c|c|c|}
\hline Study or Subgroup & \multicolumn{3}{|c|}{ Experimental } & \multicolumn{3}{|c|}{ Control } & \multicolumn{3}{|c|}{ Std. Mean Difference } & $\begin{array}{l}\text { Std. Mean Difference } \\
\text { IV, Fixed, } 95 \% \mathrm{CI}\end{array}$ & \\
\hline Fillingham, 2016 & 3 & 1 & 34 & 3 & 1 & 37 & $22.8 \%$ & $0.00[-0.47,0.47]$ & & & \\
\hline Kayupovt, 2017 & 2 & 1 & 40 & 2 & 1 & 40 & $25.8 \%$ & $0.00[-0.44,0.44]$ & & & \\
\hline Luo, 2017 & 3.43 & 0.95 & 60 & 3.58 & 1.17 & 60 & $38.5 \%$ & $-0.14[-0.50,0.22]$ & & & \\
\hline Zohar, 2004 & 8 & 2 & 20 & 8 & 2 & 20 & $12.9 \%$ & $0.00[-0.62,0.62]$ & & & \\
\hline Total $(95 \% \mathrm{Cl})$ & & & 154 & & & 157 & $100.0 \%$ & $-0.05[-0.28,0.17]$ & & 1 & \\
\hline \multicolumn{6}{|c|}{$\begin{array}{l}\text { Heterogeneity: } \mathrm{Chi}^{2}=0.36, \mathrm{df}=3(P=0.95) ; \mathrm{I}^{2}=0 \% \\
\text { Test for overall effect: } Z=0.47(P=0.63)\end{array}$} & & & & $!_{-10}$ & $\begin{array}{l}1 \\
0 \\
\text { oral intravenous }\end{array}$ & 10 \\
\hline
\end{tabular}

Fig. 7 Pooled analysis of length of hospital stay between oral administration and intravenous administration

Admittedly, there were a few limitations in the current study that should not be ignored. First, the main strength of this article is the use of a well-maintained and updated database. Nevertheless, due to all included studies' retrospective nature, bias still exist, and this may impact the comparison of clinical outcomes. Second, several potential variations, such as hemodilution, dosing strategies and timing of oral TXA, may affect estimated blood loss [20]. However, these variations provided insufficient data. Thus, there was no strong statistical evidence to analyze. Thirdly, the cost is another important evidence to help to inform decision-making when choosing the standard treatment option of TXA. The therapeutic attempts are justifiable if the better efficacy as well as cost savings can be achieved.

\section{Conclusion}

Oral TA was non-inferior to IV TA for blood-sparing efficacy without increasing the risk of thromboembolic diseases in THA and TKA. The efficiency, safety, and cost are considered to be crucial parameters during the decisionmaking of TXA routes, whether oral TXA can stands as an optimal administration of reducing blood loss following the THA and TKA compared with the IV and other forms still remains a matter of debate in future.

\section{Acknowledgements}

None.

\section{Funding}

This study was supported by Nature Science Foundation of Hubei Province (No. 2018CFB353).

\section{Availability of data and materials}

The datasets generated and analyzed during the current study are available from the corresponding author on reasonable request.

\section{Authors' contributions}

$\mathrm{XH}$ and $\mathrm{ML}$ have made substantial contributions to conception and design of the study; GG, NH and ML searched literature, extracted data from the collected literature and analyzed the data; XH wrote the manuscript; ML revised the manuscript; All authors approved the final version of the manuscript.

Ethics approval and consent to participate Not applicable.

\section{Consent for publication}

Not applicable.
Competing interests

The authors declare that they have no competing interests.

\section{Publisher's Note}

Springer Nature remains neutral with regard to jurisdictional claims in published maps and institutional affiliations.

\section{Author details}

${ }^{1}$ Department of Orthopedics, Jinan Zhangqiu District Hospital of Traditional Chinese Medicine, No. 1463 Xiushui Street,Mingshui subdistrict office, Zhangqiu district, Jinan 250200, Shandong, China. ${ }^{2}$ Clinical Laboratory, Jinan Zhangqiu District Hospital of Traditional Chinese Medicine, No. 1463 Xiushui Street,Mingshui subdistrict office, Zhangqiu district, Jinan 250200, Shandong, China. ${ }^{3}$ Department of Intensive Care Unit, Wuhan No.1 Hospital, No.215 Zhongshan Ave, Wuhan 430022, Hubei, China.

Received: 22 October 2018 Accepted: 22 November 2018

Published online: 03 December 2018

\section{References}

1. Singh JA. Epidemiology of knee and hip arthroplasty: a systematic review. Open Orthop J. 2011;5(1):80-5.

2. Kirksey M, Chiu YL, Ma Y, et al. Trends in in-hospital major morbidity and mortality after total joint arthroplasty: United States 1998-2008. Anesth Analg. 2012;115(2):321-7.

3. Ponnusamy KE, Kim TJ, Khanuja HS. Perioperative Blood Transfusions in Orthopaedic Surgery. J Bone Joint Surg Am Vol. 2014;96(21):1836.

4. Carson JL, Duff A, Poses RM, et al. Effect of anaemia and cardiovascular disease on surgical mortality and morbidity. Lancet. 1996;348(9034):1055-60.

5. Okamoto S, Hijikataokunomiya A, Wanaka K, et al. Enzyme-controlling medicines: introduction. Semin Thromb Hemost. 1997;23(06):493-501.

6. Irisson E, Hémon Y, Pauly $\mathrm{V}$, et al. Tranexamic acid reduces blood loss and financial cost in primary total hip and knee replacement surgery. Orthop Traumatol Surg Res Otsr. 2012;98(5):477-83.

7. Diblasi JF, Smith RP, Garavaglia J, et al. Comparing cost, efficacy, and safety of intravenous and topical tranexamic acid in Total hip and knee arthroplasty. Am J Orthop. 2016;45(7):E439-43.

8. Yue C, Kang P, Yang P, et al. Topical application of tranexamic acid in primary total hip arthroplasty: a randomized double-blind controlled trial. J Arthroplasty. 2014;29(12):2452-6.

9. Chen JY, Chin PL, Moo IH, et al. Intravenous versus intra-articular tranexamic acid in total knee arthroplasty: a double-blinded randomised controlled noninferiority trial. Knee. 2016:23(1):152-6.

10. Lin ZX, Woolf SK. Safety, efficacy, and cost-effectiveness of tranexamic acid in orthopedic surgery. Orthopedics. 2016;39(2):119-30.

11. Fillingham YA, Kayupov E, Plummer DR, et al. The James a. Rand young Investigator's award: a randomized controlled trial of Oral and intravenous tranexamic acid in Total knee arthroplasty: the same efficacy at lower cost? J Arthroplasty. 2016;31(9):26-30.

12. Kim JL, Park JH, Han SB, et al. Allogeneic blood transfusion is a significant risk factor for surgical-site infection following Total hip and knee arthroplasty: a meta-analysis. J Arthroplasty. 2017;32(1):320.

13. Chen Y, Chen Z, Cui S, et al. Topical versus systemic tranexamic acid after total knee and hip arthroplasty:a meta-analysis of randomized controlled trials. Medicine. 2016;95(41):e4656. 
14. Higgins JPT, Thompson SG. Quantifying heterogeneity in a meta-analysis. Stat Med. 2002;21:1539-58.

15. Higgins JPT, Thompson SG, Deeks JJ, Altman DG. Measuring inconsistency in meta-analyses. BMJ. 2003;327:557.

16. Zohar $\mathrm{E}$, Ellis $\mathrm{M}$, Ifrach $\mathrm{N}$, et al. The postoperative blood-sparing efficacy of oral versus intravenous tranexamic acid after total knee replacement. Anesth Analg. 2004;99(6):1679.

17. Irwin A, Khan SK, Jameson SS, et al. Oral versus intravenous tranexamic acid in enhanced-recovery primary total hip and knee replacement: results of 3000 procedures. Bone Joint J. 2013;95-B(11):1556-61.

18. Kayupov E, Fillingham YA, Okroj K, et al. Oral and intravenous tranexamic acid are equivalent at reducing blood loss following Total hip arthroplasty: a randomized controlled trial. J Bone Joint Surg Am Vol. 2017;99(5):373-8.

19. Yuan X, Li B, Wang Q, et al. Comparison of 3 Routes of Administration of Tranexamic Acid on Primary Unilateral Total Knee Arthroplasty: A Prospective, Randomized, Controlled Study. J Arthroplasty. 2017;32(9):2738-43.

20. Cao G, Huang Z, Xie J, et al. The effect of oral versus intravenous tranexamic acid in reducing blood loss after primary total hip arthroplasty: a randomized clinical trial. Thromb Res. 2018;164:48.

21. Gortemoller MA, Allen B, Forsyth R, et al. Comparison of Oral and intravenous tranexamic acid for prevention of perioperative blood loss in Total knee and Total hip arthroplasty. Ann Pharmacother. 2018:52(3):246-50.

22. Luo ZY, Wang HY, Wang D, et al. Oral vs Intravenous vs Topical Tranexamic Acid in Primary Hip Arthroplasty: A Prospective, Randomized, Double-Blind, Controlled Study. J Arthroplasty. 2017;33(3):786-93.

23. Wang $\mathrm{D}$, Wang HY, Cao C, et al. Tranexamic acid in primary total knee arthroplasty without tourniquet: a randomized, controlled trial of oral versus intravenous versus topical administration. Sci Rep. 2018:8(1):13579.

24. Imai N, Dohmae Y, Suda K, et al. Tranexamic acid for reduction of blood loss during total hip arthroplasty. J Arthroplasty. 2012;27(10):1838-43.

25. Malhotra R, Kumar V, Garg B. The use of tranexamic acid to reduce blood loss in primary cementless total hip arthroplasty. Eur J Orthop Surg Traumatol. 2011;21(2):101-4.

26. Alshryda S, Mason J, Vaghela M, et al. Topical (intra-articular) tranexamic acid reduces blood loss and transfusion rates following total knee replacement: a randomized controlled trial (TRANX-K). J Bone Joint Surg Am Vol. 2013:95(21):1961-8.

27. Wang J, Wang Q, Zhang X, et al. Intra-articular Application is More Effective Than Intravenous Application of Tranexamic Acid in Total Knee Arthroplasty: A Prospective Randomized Controlled Trial. J Arthroplasty. 2017;32(11):3385-9.

28. Sun Q, Yu X, Wu J, et al. Efficacy of a Single Dose and an Additional Dose of Tranexamic Acid in Reduction of Blood Loss in Total Knee Arthroplasty. J Arthroplasty. 2016;32(7):2108-12.

29. Sun Q, Yu X, Nie X, et al. The efficacy comparison of tranexamic acid for reducing blood loss in Total knee arthroplasty at different dosage time. J Arthroplasty. 2016;32(1):33-6.

30. Liu X, Zhang X, Chen Y, et al. Hidden blood loss after total hip arthroplasty. J Arthroplasty. 2011;26(7):1100-1105.e1.

31. Ervens J, Marks C, Hechler M, et al. Effect of induced hypotensive anaesthesia vs isovolaemic haemodilution on blood loss and transfusion requirements in orthognathic surgery: a prospective, single-blinded, randomized, controlled clinical study. Int J Oral Maxillofac Surg. 2010;39(12):1168-74.

32. Lasocki S, Krauspe R, Von HC, et al. PREPARE: the prevalence of perioperative anaemia and need for patient blood management in elective orthopaedic surgery: a multicentre, observational study. Eur J Anaesthesiol. 2015;32(3):160

33. Spahn DR, Casutt M. Eliminating blood transfusions: new aspects and perspectives. Anesthesiology. 2000;93(1):242-55.

34. Padhi S, Bullock I, Li L, Stroud M, National Institute for H, Care Excellence Guideline Development G. Intravenous fluid therapy for adults in hospital: summary of NICE guidance. BMJ. 2013:347:f7073.

35. Lucaspolomeni MM, Delaval Y, Menestret $\mathrm{P}$, et al. A case of anaphylactic shock with tranexamique acid (Exacyl). Annales Francaises Danesthesie Et De Reanimation. 2004;23(6):607.

36. Wang $C$, Han Z, Zhang T, et al. The efficacy of a thrombin-based hemostatic agent in primary total knee arthroplasty: a meta-analysis. J Orthop Surg Res. 2014;9(1):90

Ready to submit your research? Choose BMC and benefit from:

- fast, convenient online submission

- thorough peer review by experienced researchers in your field

- rapid publication on acceptance

- support for research data, including large and complex data types

- gold Open Access which fosters wider collaboration and increased citations

- maximum visibility for your research: over $100 \mathrm{M}$ website views per year

At $\mathrm{BMC}$, research is always in progress.

Learn more biomedcentral.com/submissions 